\title{
Improvement of enzymatic hydrolysis of a marine macro-alga by dilute acid hydrolysis pretreatment
}

\author{
Parviz Yazdani ${ }^{1 *}$, Keikhosro Karimi ${ }^{1,2}$, Mohammad J. Taherzadeh ${ }^{2}$ \\ ${ }^{1}$ Department of Chemical Engineering, Isfahan University of Technology, Isfahan, 84156-83111, Iran \\ ${ }^{2}$ School of Engineering, University of Borås, Borås 501 90, Sweden. \\ * Corresponding author. Tel: +983113915623, Fax:+983113912677, E-mail: p.yazdani@ce.iut.ac.ir
}

\begin{abstract}
The marine macro-alga Nizimuddinia zanardini was harvested from Persian Gulf to assess its biomass for fermentable sugar production. Hydrolysis of the macro-alga was investigated in two stages to evaluate the conversion of cellulose and hemicelluloses in biomass to corresponding monomeric sugars. The biomass was first subjected to dilute sulfuric acid pretreatments at $121{ }^{\circ} \mathrm{C}$ and then to enzymatic saccharification $\left(45^{\circ} \mathrm{C}, \mathrm{pH}\right.$ 4.8 ) at different retention times. The results showed the ability of the first stage hydrolysis in depolymerization of xylan to xylose with a maximum yield of $64 \%$ (based on total xylose content) at $7 \%(\mathrm{w} / \mathrm{w})$ acid concentration for $60 \mathrm{~min}$. However, the yield of glucose from glucan was relatively low in the acid hydrolysis with a maximum of $14.4 \%$ (based on total glucan content) at $7 \%(\mathrm{w} / \mathrm{w})$ acid concentration for $60 \mathrm{~min}$. Under these conditions, no hydroxymethyl furfural (HMF) produced. Formation of furfural depended on the retention time and acid concentration, whereas the concentration of acetic acid was almost constant at retention times higher than 45 min and acid concentration of $7 \%$.The solid residuals were then subjected to enzymatic hydrolysis. The maximum yield of glucose from the macro-alga by enzymatic saccharification $\left(45^{\circ} \mathrm{C}, \mathrm{pH} 4.8,24 \mathrm{~h}\right)$, using cellulase and $\beta$ glucosidase, was $70.2 \mathrm{~g} / \mathrm{kg}$ (70.2\% yield based on total glucan content).
\end{abstract}

Keywords: Enzymatic hydrolysis, Dilute-acid hydrolysis, Macro-alga, Pretreatment.

\section{Introduction}

Considering the expected decline in production of crude oil within a few years and growing concerns about enhanced global warming, production of non-fossil fuels that can cover the crude oil deficit is desirable. One such sources of energy are biofuels which can be produced by fermentation of sugar by microorganisms. Raw materials for these processes are usually obtained from agricultural products. However, if the biofuel industry is to expand in a near future, it is widely recognized that nonfood resources should be used [1].

The production of ethanol from feedstock, other than agriculture materials, has been developed in recent years and third generation biofuels are considered to be technically viable alternative bioenergy resource that is devoid of the major drawbacks. Marine resources have played an important role in biotechnology, particularly in the past decade. Previous studies of algal biofuel production have largely focused on microalgae [1], although there are several macro-algae which contain intracellular carbohydrates and have a potential for production of biofuels e.g. bioethanol and bio-oil. Nizimuddinia zanardini is among the macro-algae which contains appreciating amounts of cellulose. However, cellulose is a high molecular weight crystalline polymer which is highly stable and recalcitrant to enzymatic hydrolysis. Therefore, a pretreatment process is typically necessary for efficient conversion of cellulose to sugars. Dilute-acid treatment has been successfully developed for pretreatment of cellulosic materials. The pretreatment can enhance the carbohydrates available for enzymatic hydrolysis and fermentation. Aqueous pre-treatment at elevated temperatures result in an insoluble celluloserich fraction and a soluble fraction, containing hemicelluloses sugars and degradation products. It results in enrichment of the hard to digest materials in hydrolysate, and improves the yield of ethanol from the substrate [2]. 


\section{Methodology}

\subsection{Nizimuddinia zanardini}

Nizimuddinia zanardini used in all the experiments which was obtained from Persian Gulf (Chabahar Coastline, Iran). It was dried at $45^{\circ} \mathrm{C}$ for 24 hour and milled in a hammer mill to pass through a $1.27 \mathrm{~mm}$ screen. The milled macro-alga was stored at $-5^{\circ} \mathrm{C}$.

\subsection{Hydrolysis}

Prior to the hydrolysis experiments, 5 gram of the biomass was soaked in 100 ml dilute $\mathrm{H}_{2} \mathrm{~S}_{4}$ $(7 \%, 3.5 \%$, and $0.5 \% \mathrm{w} / \mathrm{w})$ and pretreated in an autoclave at $121^{\circ} \mathrm{C}$ for different retention times $(30,45$, and $60 \mathrm{~min})$. It was then cooled and the liquor was drained. The dilute acid treated solid materials were then subjected to enzymatic hydrolysis using commercial cellulase (15 FPU/g dry biomass) and $\beta$-glucosidase (45 IU/g dry biomass) in $75 \mathrm{ml}$ citrate buffer $(\mathrm{PH}=4.8)$ for 24 and 48 hours.

\subsection{Analysis}

All the liquids were analyzed by high-performance liquid chromatography (HPLC), equipped with UV/VIS and RI detectors (Jasco International Co., Tokyo, Japan). Glucose and xylose were determined by an Supelcogel Pb HPLC column at $80{ }^{\circ} \mathrm{C}$. Deionized water was used as eluent at a flow rate of $0.6 \mathrm{ml} / \mathrm{min}$. Acetic acid, furfural, and HMF were analyzed on an Aminex HPX-87H column (Bio-Rad) at $60{ }^{\circ} \mathrm{C}$ with $0.6 \mathrm{ml} / \mathrm{min}$ eluent of $0.005 \mathrm{M}$ sulfuric acid. Concentrations of glucose, xylose, and acetic acid were determined by RI detector, while furfural and HMF were quantified on UV chromatograms at $210 \mathrm{~nm}$.

The macro-alga was also analyzed for glucan and xylan following the procedure described in NREL Chemical Analysis \& Testing Procedure [3] and the results are summarized in (Table $1)$.

Table 1. Composition of Nizimuddinia zanardini.

\begin{tabular}{cc}
\hline Carbohydrate & $(\mathrm{g} / \mathrm{Kg}$ dry substrate $)$ \\
\hline Glucan & 100 \\
Xylan & 30 \\
Galactan & 70 \\
Mannitol & 150 \\
Fructosan & 50 \\
Arabinan & 15 \\
\hline
\end{tabular}

\section{Results and discussion}

There are a few research has been performed on the pretreatment and enzymatic saccharification of marine macro-algae [4]. During pretreatment, it is possible to solubilize the hemicellulose to fermentable sugars [5]. However, depending on the temperature, the pretreatment usually produces sugar degradation products such as furfural and HMF, which known to be sever inhibitors for fermentative microorganisms [6,7]. Dilute acid pretreatment can be used for improvement of enzymatic saccharification beside the hydrolysis of hemicelluloses.

Dilute acid hydrolysis of macro-alga was performed at different acid concentration of 7, 3.5, and $0.5 \%$ at $120{ }^{\circ} \mathrm{C}$. The most important results of the acid hydrolysis were summarized in Figs. 1-6. 


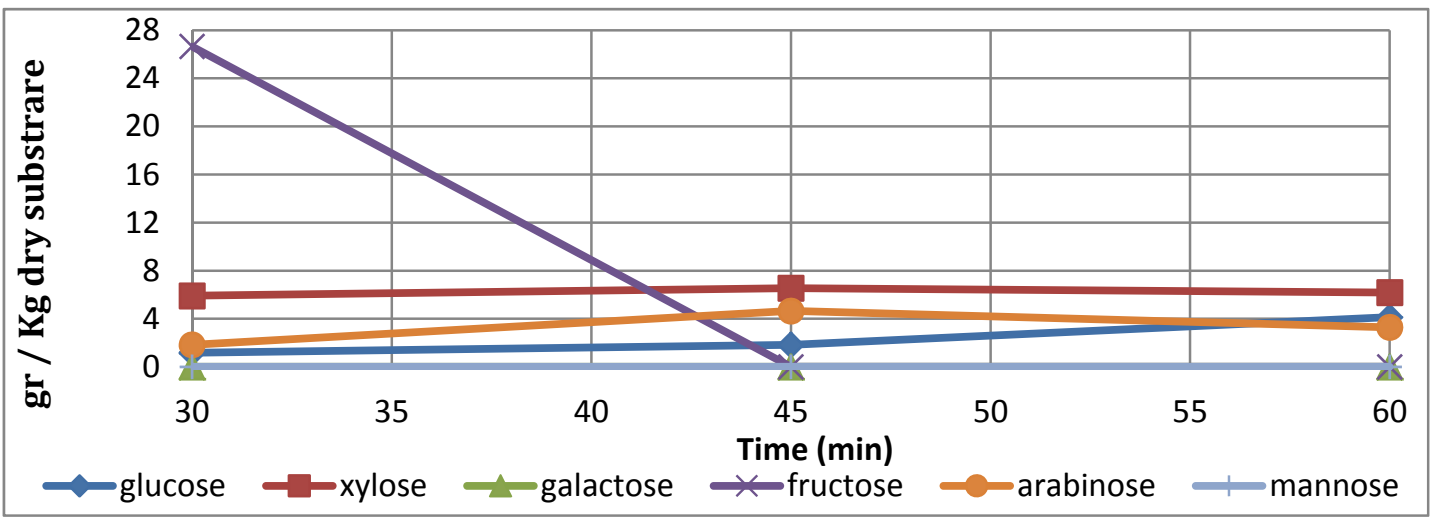

Fig. 1. The effect of retention time on the yields of glucose, xylose, galactose, fructose, arabinose and mannose production with $0.5 \% \mathrm{H}_{2} \mathrm{SO}_{4}$.

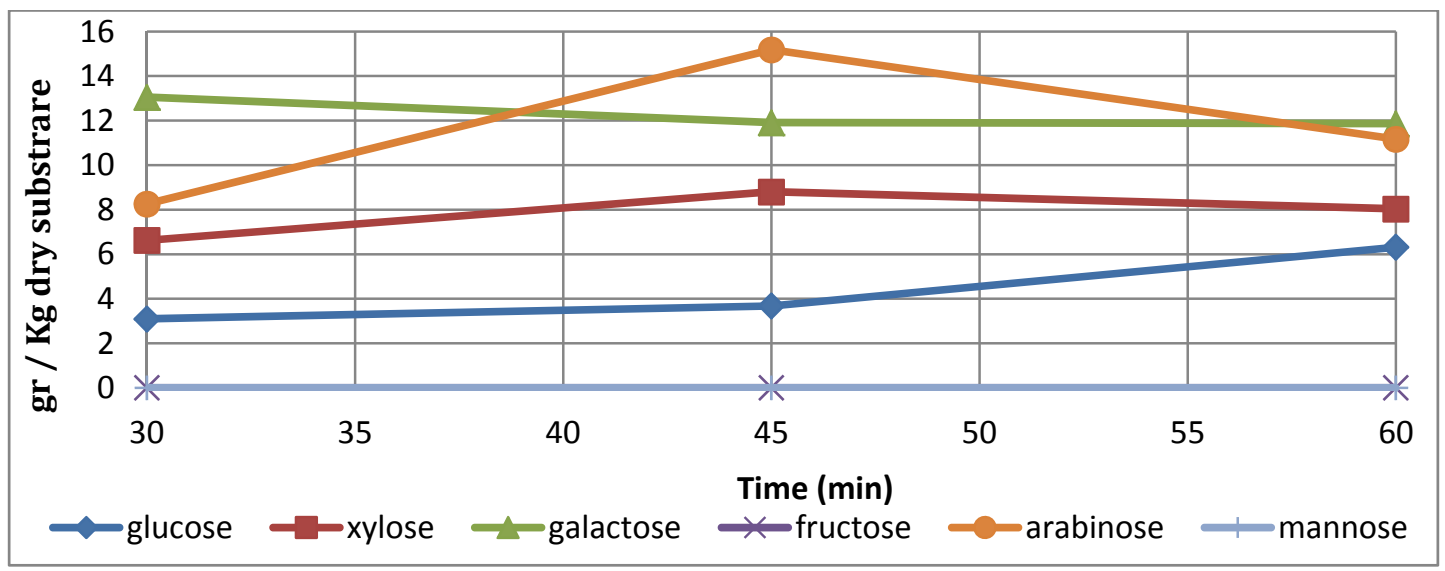

Fig.2. The effect of retention time on the yields of glucose, xylose, galactose, fructose, arabinose, and mannose production with $3.5 \% \mathrm{H}_{2} \mathrm{SO}_{4}$.

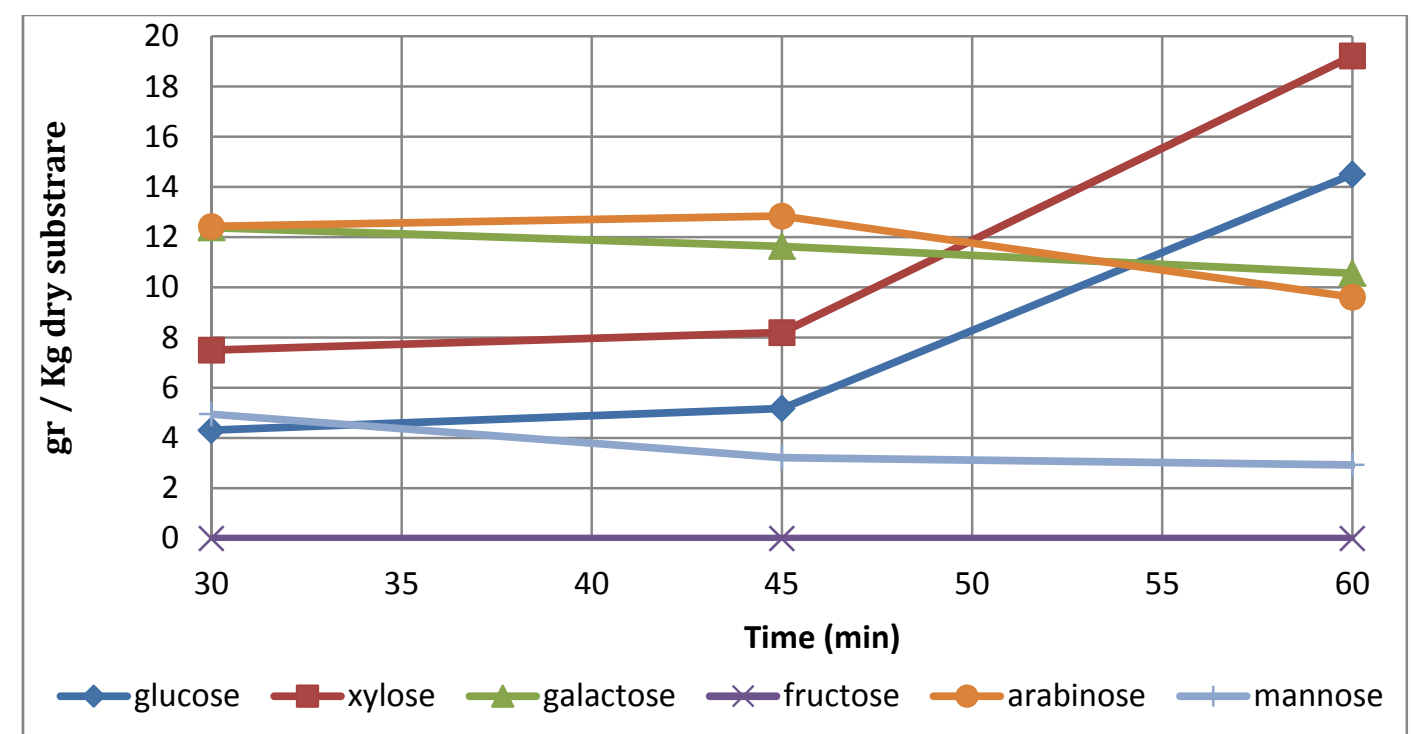

Fig. 3. The effect of retention time on the yields of glucose, xylose, galactose, fructose, arabinose and mannose production with $7 \% \mathrm{H}_{2} \mathrm{SO}_{4}$. 


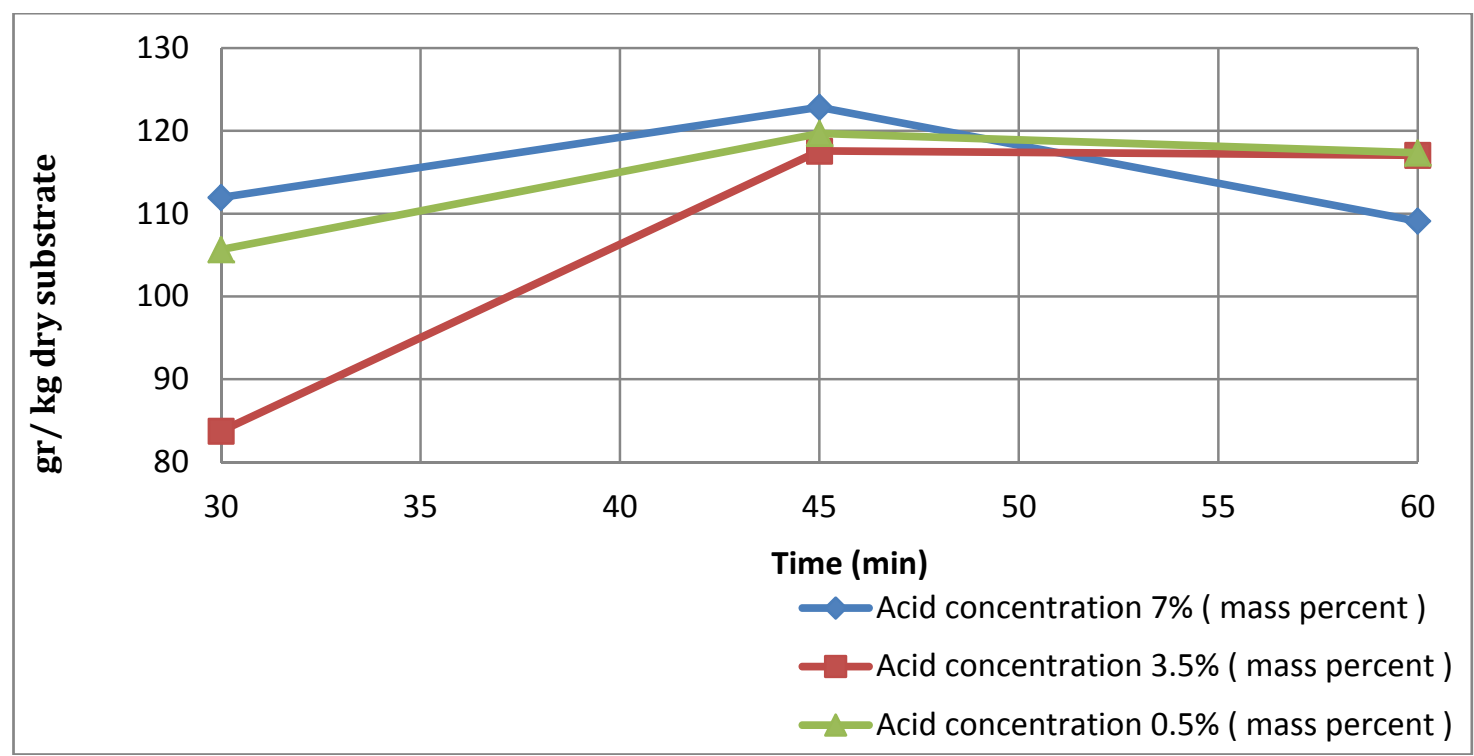

Fig. 4. The effect of retention time on the yields of mannitol by $7 \%, 3.5 \%$ and $0.5 \% \mathrm{H}_{2} \mathrm{SO}_{4}$.

A comparison of the maximum yields of xylose and glucose (fig. 3) with the xylan and glucan content of the macro-alga (Table. 1) showed the ability of the first stage hydrolysis to depolymerize xylan and glucan to maximum yields of $64 \%$ and $14.7 \%$ of the theoretical xylan and glucan contents, respectively. Theoretical xylose and glucose yields were calculated based on the total content of xylan and glucan in the macro-alga.

Increasing the retention time of hydrolysis from 30 to 45 min showed negligible effects on formation of glucose, but the yields of xylose, mannitol, galactose, furfural, and acetic acid were significantly affected (Fig. 1-6). It indicated that $30 \mathrm{~min}$ hydrolysis at $0.5-7 \%$ acid concentration is not enough to depolymerize the hemicelluloses of the biomass. On the other hand, since the concentration of acetic acid reached the maximum concentration $(31.8 \mathrm{~g} / \mathrm{kg})$ in $60 \mathrm{~min}$ hydrolysis at $7 \%$ acid concentration, it indicated complete hydrolysis of the hemicellulose within $60 \mathrm{~min}$, and the optimum retention time should be sometimes between 45 and 60 min (Fig. 5).

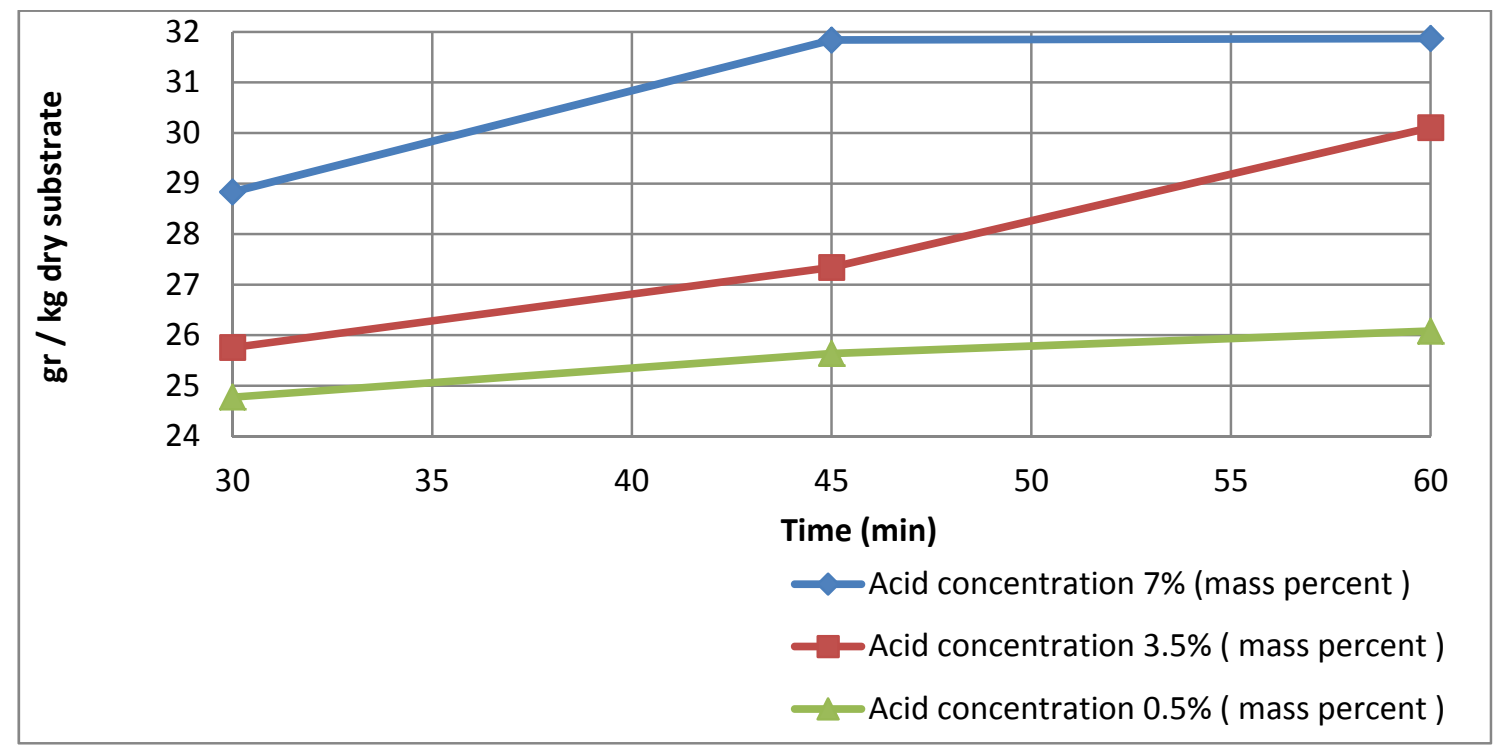

Fig. 5. The effect of retention time on the yields of acetic acid production with $7 \%, 3.5 \%$ and $0.5 \%$ $\mathrm{H}_{2} \mathrm{SO}_{4}$. 
Furans, i.e. furfural and hydroxymethyl furfural (HMF), have inhibitory effect on ethanol production yields by fermentation. In this work, maximum yield of furfural was observed at $7 \%$ acid concentration and 60 min retention time, while HMF was not detected during all experiments (Fig. 6).

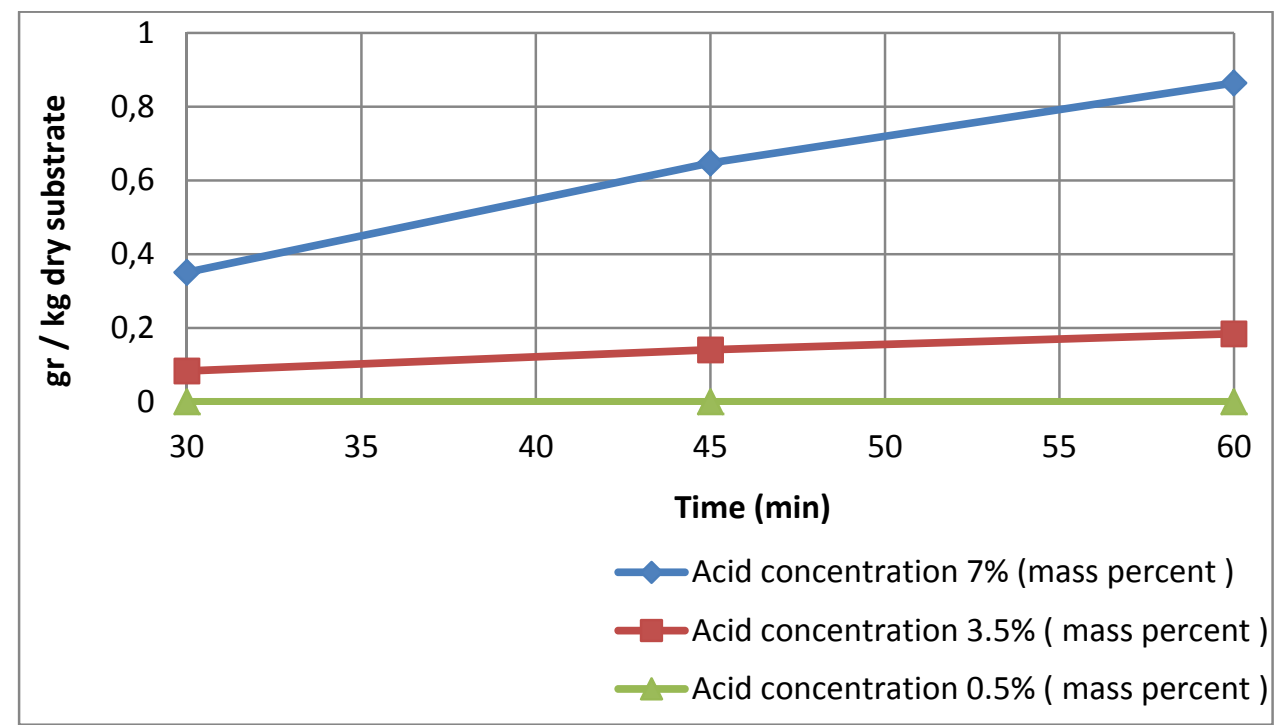

Fig. 6. The effect of retention time on the yield of furfural formation with $7 \%, 3.5 \%$ and $0.5 \% \mathrm{H}_{2} \mathrm{SO}_{4}$

At the second stage hydrolysis, the residual solids (Table. 2) subjected to enzymatic scarification by cellulase and $\beta$-glucosidase.

Table 2. The residual solids remaining after dilute acid hydrolysis.

\begin{tabular}{cc}
\hline Test case & Mass of substrate $(\mathrm{g})$ \\
\hline $7 \%, 60 \mathrm{~min}$ & 0.8043 \\
$7 \%, 45 \mathrm{~min}$ & 1.2497 \\
$7 \%, 30 \mathrm{~min}$ & 1.2509 \\
$3.5 \%, 60 \mathrm{~min}$ & 0.8135 \\
$3.5 \%, 45 \mathrm{~min}$ & 0.9158 \\
$3.5 \%, 30 \mathrm{~min}$ & 1.2326 \\
$0.5 \%, 60 \mathrm{~min}$ & 1.1850 \\
$0.5 \%, 45 \mathrm{~min}$ & 1.2627 \\
$0.5 \%, 30 \mathrm{~min}$ & 1.4077 \\
\hline
\end{tabular}

The yield of substrate without pretreatment for glucose after 24 hour incubation was only $2.98 \%$ of the dry substrate (Table. 3 ).

Table 3. Enzymatic hydrolysis results without pretreatment

\begin{tabular}{cc}
\hline Sugar & yield $(\mathrm{g} / \mathrm{kg}$ of dry substrate) \\
\hline Glucose & 29.8 \\
Xylose & 10.05 \\
Galactos & 4.72 \\
Mannitol & 38.4 \\
Mannose & 1.0 \\
Fructose & 0 \\
Arabinose & 3.51 \\
\hline
\end{tabular}


Among the all experiments, pretreatment with 7\% sulfuric acid for $45 \mathrm{~min}$ and 24 hours enzymatic hydrolysis yielded the highest glucose in the enzymatic hydrolysates (Fig 7).

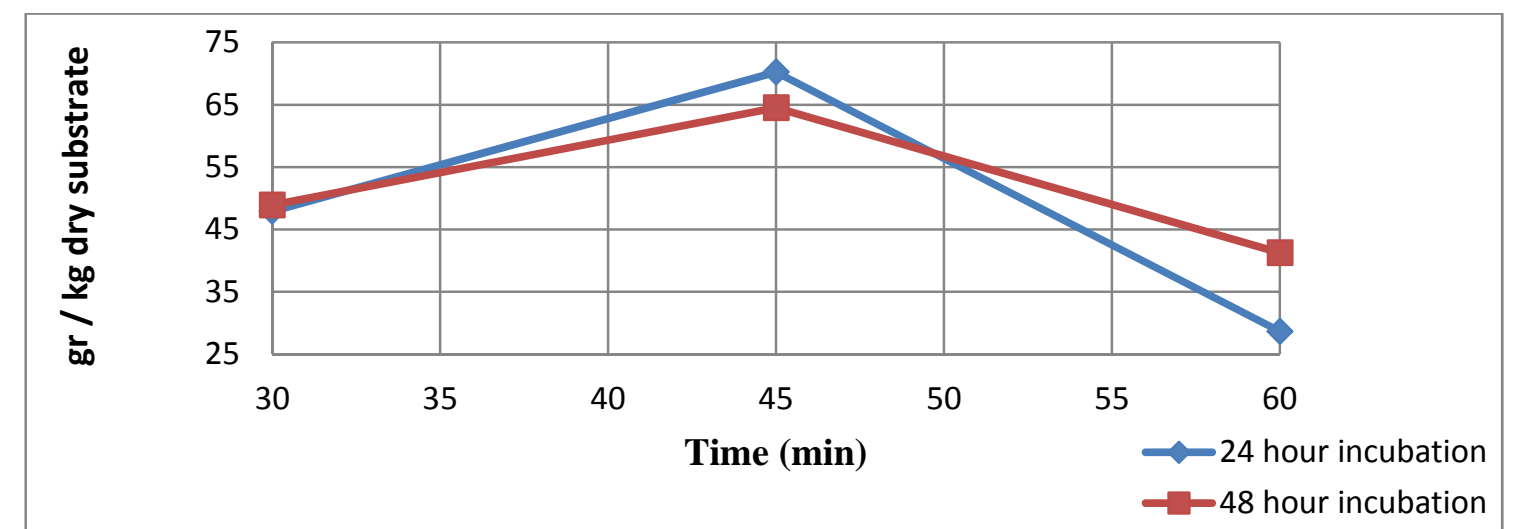

Fig. 7.The effect of retention time on the yields of glucose by enzymatic hydrolysis after pretreatment with 7\% dilute acid for 30, 45, 60 min retention times.

\section{Conclusions}

It is possible to solubilize the hemicellulose to fermentable sugars by dilute acid hydrolysis. The results of this study indicated that $7 \%(\mathrm{w} / \mathrm{w}) \mathrm{H}_{2} \mathrm{SO}_{4}$ is a promising pretreatment in order to obtain high yields of sugars without sugar degradation products formation.

It is possible to obtain a saccharification yield of $70.2 \%(70.2 \mathrm{~g} / \mathrm{kg})$, based on the glucose content, by using $7 \%(\mathrm{w} / \mathrm{w})$ acid at $120^{\circ} \mathrm{C}$ for $45 \mathrm{~min}$ and saccharification with two commercial enzymes, where the yield was only $29.8 \%$ without pretreatment.

The hydrolyzate of $7 \%(\mathrm{w} / \mathrm{w})$ acid pretreatment at $120^{\circ} \mathrm{C}$ for 45 min contains mainly mannitol, which can be a suitable source for ethanol production. The hydrolyzates contains very low concentration of fermentation inhibitors.

\section{References}

[1] L. Brennan, P. Owende, Biofuels from microalgae-A review of technologies for production, processing, and extractions of biofuels and co-products, Renewable and Sustainable Energy Reviews 14, 2010, pp. 557-577

[2] M J. Taherzade, K. Karimi, Acid-base hydrolysis processes for ethanol from lignocellulosic material: a review, Bioethanol review, 2007, bioresources 2(3), pp. 472499

[3] R. Ehrman, determination of carbohydrate in biomass by high performance liquid chromatography, Chemical analysis \& testing task: NREL, LAP 002; 1996.

[4] X. Wang, X. Liu, G. Wang, Two-stage Hydrolysis of Invasive Algal Feedstock for Ethanol Fermentation, Journal of Integrative Plant Biology, no. doi: 10.1111/j.17447909.2010.01024.x.

[5] B. Saha, L. Iten, M. Cotta, Y. Wu, Dilute Acid Pretreatment, Enzymatic Saccharification, and Fermentation of Rice Hulls to Ethanol, Biotechnol. Prog, 2005, 21, pp. 816-822

[6] B.Saba, K. Hayashi, Lignocellulose biodegradation and applications in biotechnology, In Lignocellulose Biodegradation, American Chemical Society: Washington, DC, 2004, pp. 2-34.

[7] C. Saha, J. Bothast, Pretreatment and Enzymatic Saccharification of Corn Fiber, Applied Biochemistry and Biotechnology, Vol. 76, 1999,pp. 65-77 